\title{
Electrochemical synthesis of Poly[3, 4-Propylenedioxythiophene-co-N-Phenylsulfonyl Pyrrole]: Morphological, electrochemical and spectroscopic characterization
}

\author{
F. G. Guler, A. S. Sarac* \\ Istanbul Technical University, Department of Chemistry, Polymer Science and Technology, Maslak, 34469, Istanbul, \\ Turkey
}

Received 22 September 2010; accepted in revised form 16 December 2010

\begin{abstract}
Electroactive random copolymers of 3,4-Propylenedioxythiophene (ProDOT) and N-Phenylsulfonyl Pyrrole (PSP) were electrochemically synthesized on single carbon fiber microelectrode (SCFME) by cyclic voltammetry (CV). Fourier Transform Infrared-Attenuated Total Reflectance (FTIR-ATR) measurements indicate the inclusion of PSP into the copolymer structure. The influence of feed ratios on the copolymers was studied by CV and electrochemical impedance spectroscopy (EIS) and equivalent circuit modelling (ECM). The morphologies and film thicknesses of copolymers were characterized by scanning electron microscopy (SEM) and atomic force microscopy (AFM). The results have shown that the principal changes in morphology, conductivity, porous nature and thickness of Poly(ProDOT-co-PSP) film depend on the concentration of PSP. The strong electron-withdrawing sulfonyl group substitution on PSP significantly inhibited electrochemical copolymerization. Semicircular characteristics at Nyquist plots reflected an increasing trend with the increase of PSP concentration in the feed at high frequency. The semicircular characteristic of the copolymer film is useful for the bioelectrochemical sensor applications.
\end{abstract}

Keywords: polymer synthesis, molecular engineering, electrocopolymerization, copolymer of ProDOT, Electrochemical Impedance Spectroscopy

\section{Introduction}

Conductive polymers have been electrochemically preferred because of their physical or chemical properties such as volume, color, stored charge or porosity and used for a number of applications such as electrochromic displays [1-11], smart windows [12], solar cells [13-14], supercapacitors [15-16] and biosensors [17-18].

3,4-alkylenedioxythiophene based polymers exhibit low oxidation potential, high and quite stable conductivities, a high degree of optical transparency as a conductor, and the ability to be rapidly switched between conducting doped and insulating neutral states. Substitution at the 3- and 4-positions of thiophene prevents the occurrence of $\alpha-\beta$ and $\beta-\beta$ coupling during electropolymerization, yielding more ordered polymers with longer conjugation lengths. The synthesis of 3,4-disubstituted polythiophenes was carried out stabilizing the oxidized form, providing solubility, processability [19].

Poly(ProDOT) was synthesized by the traditional double-Williamson etherification route, having $\Delta \lambda \% \mathrm{~T}$ of $66 \%$ at $\lambda_{\max }$ compared to the $54 \%$ transmittance change for PEDOT [20]. ProDOT exhibited higher contrast in comparison to conjugated polymers from EDOT [1].

\footnotetext{
${ }^{*}$ Corresponding author, e-mail: sarac@itu.edu.tr
} (c) BME-PT 
Side-chain derivatization is possible due to ProDOT flexibility of the conjugated backbone structure. The dimethyl and diethyl derivatives especially exhibit enhanced electrochromic contrasts throughout the visible region [21] and high capacitive behaviors [15-16]. A series of Poly(ProDOTs) are disubstituted with long chain esters. This functionality enhances solubility in polar solvents [22]. Electropolymerization of hydroxymethyl-substituted 3, 4-Propylene dioxythiophene monomer (ProDOT-OH) was easily performed [23]. Multiwalled carbon nanotubes (MWNTs) were functionalized with Poly(ProDOT) by oxidative polymerization and MWNT-g-PProDOT hybrid was prepared and showed that improved thermal stability [24].

Films of conjugated polymers are generally synthesized onto a support electrode surface by electropolymerization (anodic oxidation) of the corresponding monomer in the presence of an electrolyte solution. Carbon fibers have highly accessible surface area, low resistivity and high stability which consist of stacked hexagonal carbon layers, forming small coherent units (crystallites) of only a few micrometers in the stacking direction [25]. Electropolymerization on carbon fiber microelectrode (CFME) can improve the interfacial properties between the carbon fiber and polymeric matrix. Generally electrocoating of conjugated polymers on carbon fiber easily allows the characterization of the deposited films by spectroscopic, morphological and electrochemical techniques. Conducting polymers which were coated electrochemically onto CFMEs were studied in detail and reported by Sarac and coworkers [16, 26-33].

Electrochemical impedance spectroscopy (EIS) is a powerful technique to study charge transfer, ion diffusion and capacitance of conducting polymer modified electrodes [34-39]. EIS has been used to develop equivalent electric circuits to describe the electrochemical properties of films of conducting polymers in organic solution [40-41]. EIS has also provided information concerning corrosion protection by inhibitors [42-47].

The chemical synthesis through two different methods of N-phenylsulfonyl pyrrole (PSP) was reported and used as a gas sensitive resistor [48]. N-phenyl sulfonyl-1H-pyrrole-3-sulfonyl chloride was syn- thesized by using chromosulphonic acid in acetonitrile [49].

The copolymers from different monomers or comonomers have been synthesized by both electrochemical and chemical oxidative polymerizations to efficiently modify the structure and to improve the properties of the conducting polymers [50-55]. The electrochemical polymerization allows obtaining materials with controlled properties without suffering the experimental disadvantages [56]. In this paper, we report the electrochemical random copolymerization of ProDOT and PSP onto different working electrodes. The electrochemical and morphological properties of Poly(ProDOT) and copolymer films were characterized by FTIR-ATR, EIS, SEM and AFM. The electrochemical impedance data was fitted to an equivalent circuit in order to identify differences between the conductivities of Poly(ProDOT) and copolymers. Briefly, the effect of PSP mole fractions on the electrochemical and morphologic properties of resulting copolymers using alternative characterization techniques was shown with this paper.

\section{Experimental details}

\subsection{Chemicals and materials}

SGL SIGRAFIL C 320B (SGL Carbon Group, Meitingen, Germany; a high strength and high modulus of elasticity coupled with high electrical conductivity carbon fibers) containing single filament in a roving were used as a working electrode. ProDOT and PSP were purchased from SigmaAldrich (Germany) and used as received. Electrochemical polymerizations (electrocoatings) were performed in acetonitrile (ACN, Merck, Darmstadt, Germany) containing $\mathrm{NaClO}_{4}$ (Sigma-Aldrich, Germany) at the same scan rate $(30 \mathrm{mV} / \mathrm{s})$ and deposition cycle numbers (10 cycles) (applied charges).

\subsection{Characterization}

Electrochemical measurements (EIS with supplied Power Sine software package and Cyclic Voltammograms) were performed with a Princeton Applied Research (PAR) Parstat 2263 potentiostat (Oak Ridge, USA). The potentiostat is a self-contained unit that combines potentiostatic circuitry with phasesensitive detection. The impedance measurements were carried out by scanning in the frequency range 
$10 \mathrm{mHz}-100 \mathrm{kHz}$ with applied AC signal amplitude of $10 \mathrm{mV}$ using Power Sine. The impedance spectrum was analyzed using AC impedance data analysis software (ZSimpWin V3.10, Michigan, USA).

For spectroscopic measurements, Poly(ProDOT-coPSP) copolymers were synthesized onto ITO-PET (NV Innovative Sputtering Technology, Zulte, Belgium, PET $175 \mu \mathrm{m}$,Coating ITO-60) in the potential range from -0.8 to $1.5 \mathrm{~V}$ at a scan rate of $50 \mathrm{mV} / \mathrm{s}$ in $0.1 \mathrm{M} \mathrm{NaClO} / 4 / \mathrm{ACN}$. Polymer films on ITO-PET were analysed using an ATR-FTIR reflectance spectrometer (Perkin Elmer, Spectrum One, California, USA; having a universal ATR attachment with a diamond and ZnSe crystal C70951). Perkin Elmer Spectrum software was used to carry out FTIR-ATR measurements between $650-4000 \mathrm{~cm}^{-1}$.

Thin films of copolymers, electrocoated onto carbon fibers were analyzed by scanning electron microscopy on a Nanoeye Desktop Mini-SEM (SEC. Co., Ltd.; South Korea) The increase in the average values of film thicknesses was obtained via SEM images taking into account the diameter of the uncoated fiber. The diameters for the fibers were calculated from an average of 5-6 measurements on individual fibers.

Thin film of copolymer, electrocoated onto silicon wafer (n-doped, Cz type; Wacker Siltronic AG., München, Germany) was analyzed by atomic force microscopy (AFM) using a Nanosurf Easyscan 2 AFM (Nanoscience Instruments, Liestal ,Switzerland) instrument with a $10 \mu \mathrm{m}$ AFM head.

\subsection{Preparation of Single Carbon Fiber Microelectrodes (SCFMEs)}

A three-electrode system was used employing SCFME which was prepared by using a single carbon fiber (diameter $\sim 7 \mu \mathrm{m}$ ) that was rolled to a copper wire and fixed with a Teflon tape and inserted into a glass capillary (diameter $\sim 4.45 \mathrm{~mm}$ ) as working electrode. The single carbon fiber and copper wire were attached and connected to the potentiostat. $\sim 1 \mathrm{~cm}$ of SCFME was dipped into the electrolyte solution to keep the electrode area costant $\left(\sim 2 \cdot 10^{-3} \mathrm{~cm}^{2}\right)$. Button electrodes were prepared by using $\mathrm{Ag}$ and Pt wires in glass capillary $(\sim 4.45 \mathrm{~mm}$ diameter) filled with MMA and polymerized by UV light, which was inert against the electrolyte solution. The reference and counter electrode surface areas were kept constant $\left(\sim 0.47 \mathrm{~mm}^{2}\right)$ during the experiments.

\section{Results and discussions \\ 3.1. Electrocopolymerization of ProDOT and PSP}

ProDOT and PSP were electrochemically copolymerized on SCFMEs in the potential range from -0.8 to $1.5 \mathrm{~V}$ at a scan rate of $30 \mathrm{mV} / \mathrm{s}$ in $0.1 \mathrm{M}$ $\mathrm{NaClO}_{4} / \mathrm{ACN}$. After 10 potential cycles completed, the working electrode surfaces were washed and analyzed in monomer free solution $\left(0.1 \mathrm{M} \mathrm{NaClO}_{4} /\right.$ $\mathrm{ACN}$ ) to find out their redox behaviour at different scan rates between 15 and $200 \mathrm{mV} \cdot \mathrm{s}^{-1}$ by $\mathrm{CV}$. The amount of PSP concentration was increased from 5 to $20 \mathrm{mM}$ when ProDOT concentration was held constant $(10 \mathrm{mM})$. Three copolymers with different compositions were synthesized with by using $X_{\mathrm{PSP}}=$ $[(\mathrm{PSP} /($ ProDOT+PSP)] mole fraction [CP1 (0.33), CP2 (0.50), and CP3 (0.66)].

The potential shift to the positive direction with an increase of PSP concentration in the feed indicates that the monomer ratio affects the copolymer composition and its electrochemical properties. The obvious peak potential shift provided information about the increase in the electrical resistance in the copolymer film. As shown at multisweep cyclic voltammograms of ProDOT $(10 \mathrm{mM})$ in the presence of PSP $(5 ; 10 ; 20 \mathrm{mM})$; the intensity of the current peaks increased with increase in the number of potential cycles indicating a continuous growth of electroactive copolymer on the electrode (Figure 1a, c).

For repeated cycling the cathodic peak current decreases and the anodic one increases until a steadystate pattern. Also the current during the first cycle was quite different from that in the second cycle. After 5 cycles the system has settled down. Results obtained from multiple cycling showed that the first five cycles of the voltammogram were usually in unstable stage (Figure 1a-c). After five cycles, steady state condition $\left(6^{\text {th }}\right.$ cycle) was achieved.

Oxidation potentials ( $\left.E_{\mathrm{ONSET}}\right)$ of $\mathrm{CP} 1$ and $\mathrm{CP} 2$ were obtained as 1.139 and $1.127 \mathrm{~V}$ higher than oxidation potential of CP3 $(1.19 \mathrm{~V})$ during the electrogrowth process. This is due to increased PSP concentration in feed ratio. The strong electronwithdrawing sulfonyl group in PSP can be stabilized by using the radical cation intermediates to 

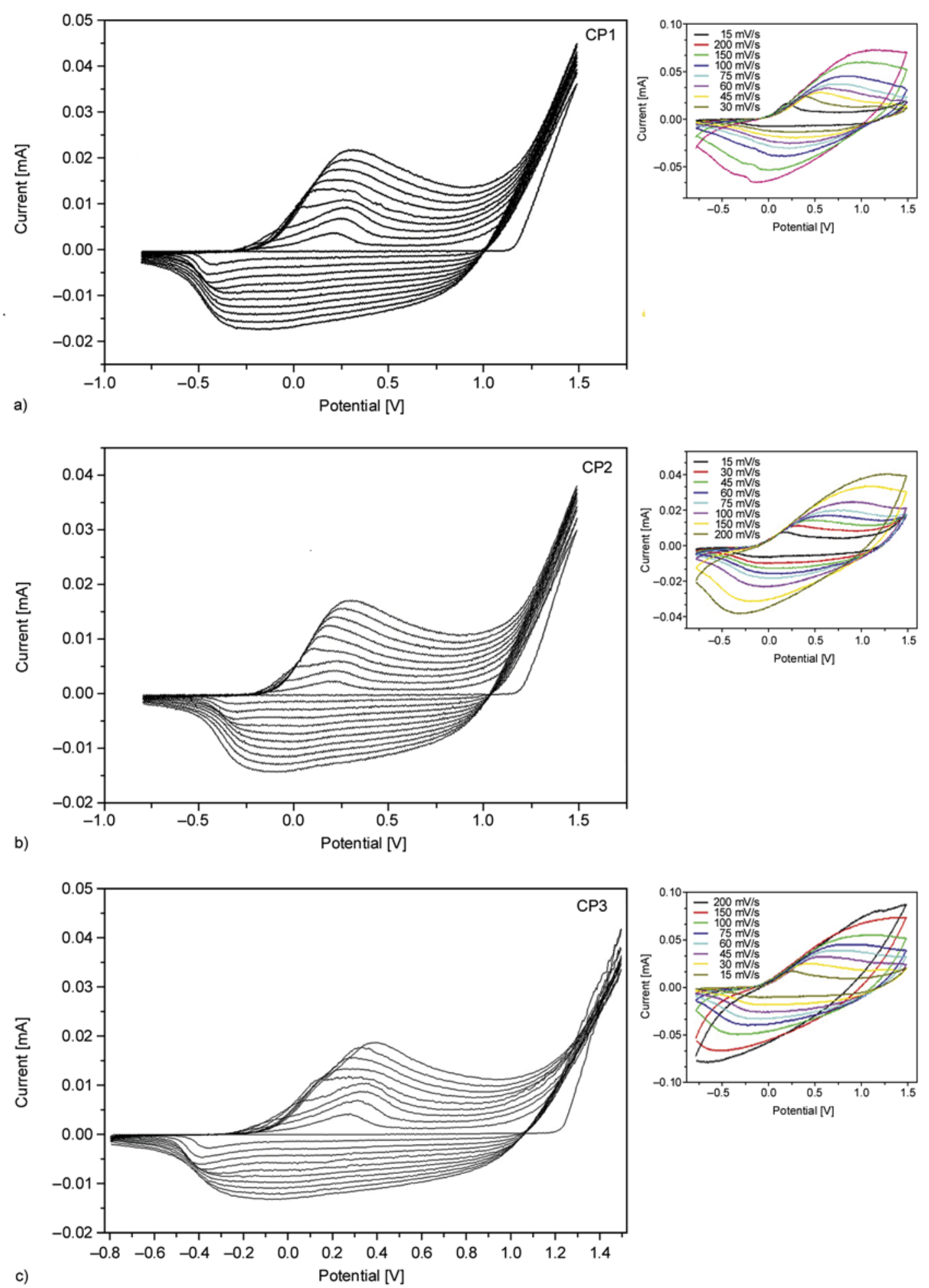

Figure 1. Cyclic voltammetry of electrogrowth of $10 \mathrm{mM}$ ProDOT and (a) $5 \mathrm{mM}$ (CP1), (b) $10 \mathrm{mM}$ (CP2), (c) $20 \mathrm{mM}$ (CP3) PSP in $0.1 \mathrm{M} \mathrm{NaClO}_{4} / \mathrm{ACN}$; scan rate: $30 \mathrm{mV} / \mathrm{s}$; scan number: 10 cycles on SCFME. Graphs on right hand side: $\mathrm{CV}$ of monomer-free diagrams belongs to Poly(ProDOT-co-PSP) in $0.1 \mathrm{M} \mathrm{NaClO} / \mathrm{ACN}$ at different scan rates $(15$ to $200 \mathrm{mV} / \mathrm{s})$

diffuse away from the electrode and thus inhibiting electropolymerization (Table 1). The peak current decreased in direct proportion with decrease of oxidation potential (Figure 2).
The anodic and cathodic peak current increased with increase in scan rate. Figure $3 a$ and $b$ show that the anodic and cathodic redox reaction for the copolymers formed in $0.1 \mathrm{M} \mathrm{NaCIO} 4 / \mathrm{ACN}$ appear to be 


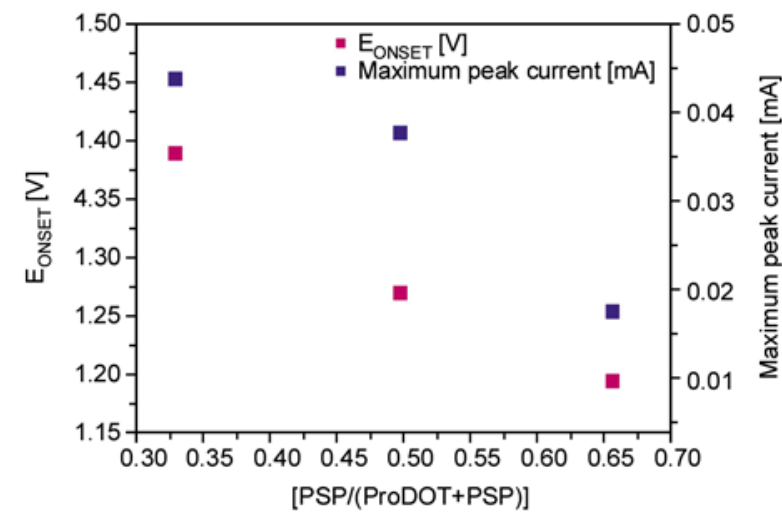

Figure 2. Plot of oxidation potential and maximum peak current obtained from $\mathrm{CV}$ for different mole fraction of Poly(ProDOT-co-PSP)

diffusion-controlled, as proved by the linearity of the plot and are extremely reversible even at high scan rates.

\subsection{Ex-situ FTIR-ATR measurements of Poly(ProDOT-co-PSP) and Poly(ProDOT)} For spectroscopic characterization of Poly(ProDOTco-PSP) films, the same mole fractions of the copoly-

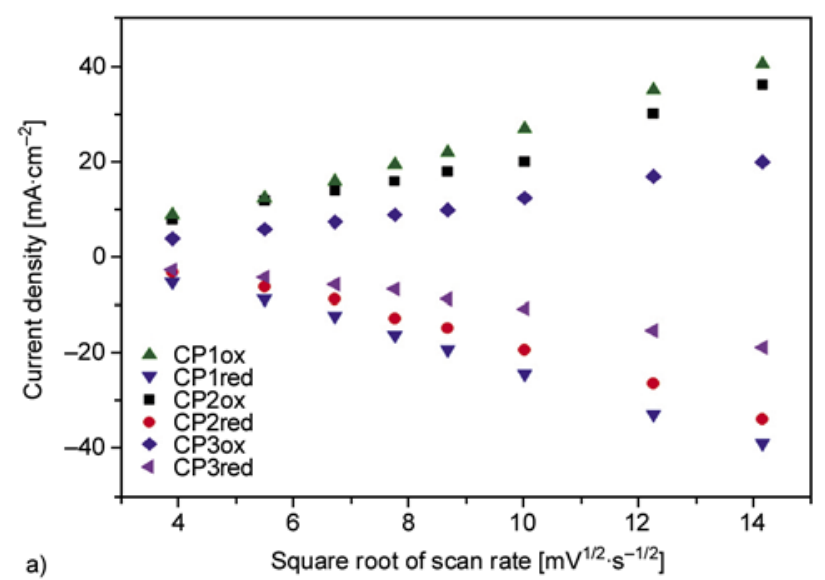

Table 1. Comparison of thickness of copolymer coated SCFME, $\triangle Q, C_{\mathrm{LF}}$ and phase angle of copolymer films

\begin{tabular}{|l|c|c|c|}
\hline \multicolumn{1}{|c|}{ Copolymers } & CP1 & CP2 & CP3 \\
\hline$\Delta Q[\mathrm{mC}]$ & 7.184 & 5.498 & 3.305 \\
\hline $\begin{array}{l}\text { Thickness of copolymer coated } \\
\text { SCFME }[\mu \mathrm{m}]\end{array}$ & 19.86 & 15.75 & 11.15 \\
\hline$C_{\mathrm{LF}}\left[\mathrm{mF} \cdot \mathrm{cm}^{-2}\right]$ & 173.5 & 172.3 & 65.5 \\
\hline$\sim i_{\mathrm{pa}}{ }^{*}[\mathrm{~mA}]$ & 0.044 & 0.038 & 0.018 \\
\hline$E_{\mathrm{ONSET}}[\mathrm{V}]$ & 1.139 & 1.127 & 1.119 \\
\hline Phase of $\left.Z{ }^{\circ}\right]$ & $66.99^{\circ}$ & $51.18^{\circ}$ & $43.28^{\circ}$ \\
\hline
\end{tabular}

${ }^{*} i_{\text {pa }}$ values are anodic current peaks, obtained from $10^{\text {th }}$ cycles of cyclic voltammograms

mers were also prepared by cyclic voltammetry on ITO-PET with the same conditions of random Poly (ProDOT-co-PSP) films formation on SCFME (Figure 4).

Inclusion of PSP into the electrocopolymerized thin film, and doping with the respective anion of the supporting electrolyte were followed by FTIR-ATR (Figure 5). This technique allows us to assign corresponding functional groups in the resulting copolymer.

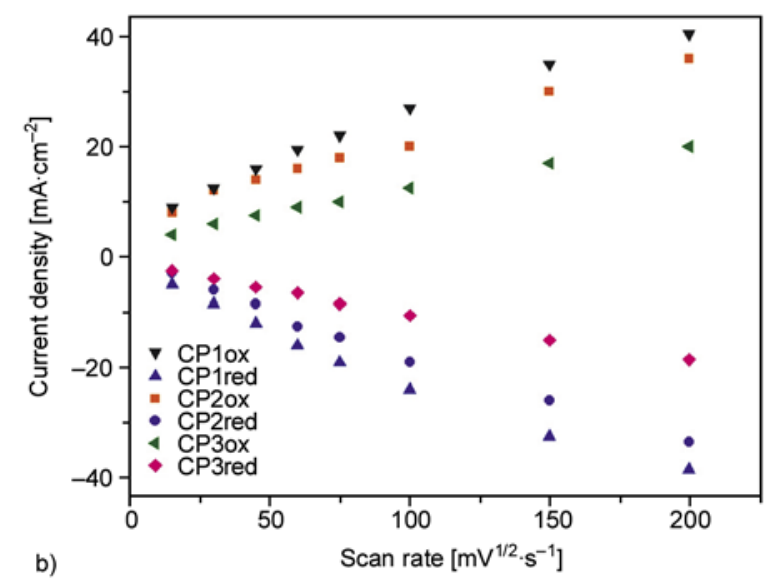

Figure 3. Plots of anodic and cathodic peak current density (a) square root of scan rate, (b) scan rate dependent on the copolymer films in monomer free solution in $0.1 \mathrm{M} \mathrm{NaClO}_{4} / \mathrm{ACN}$

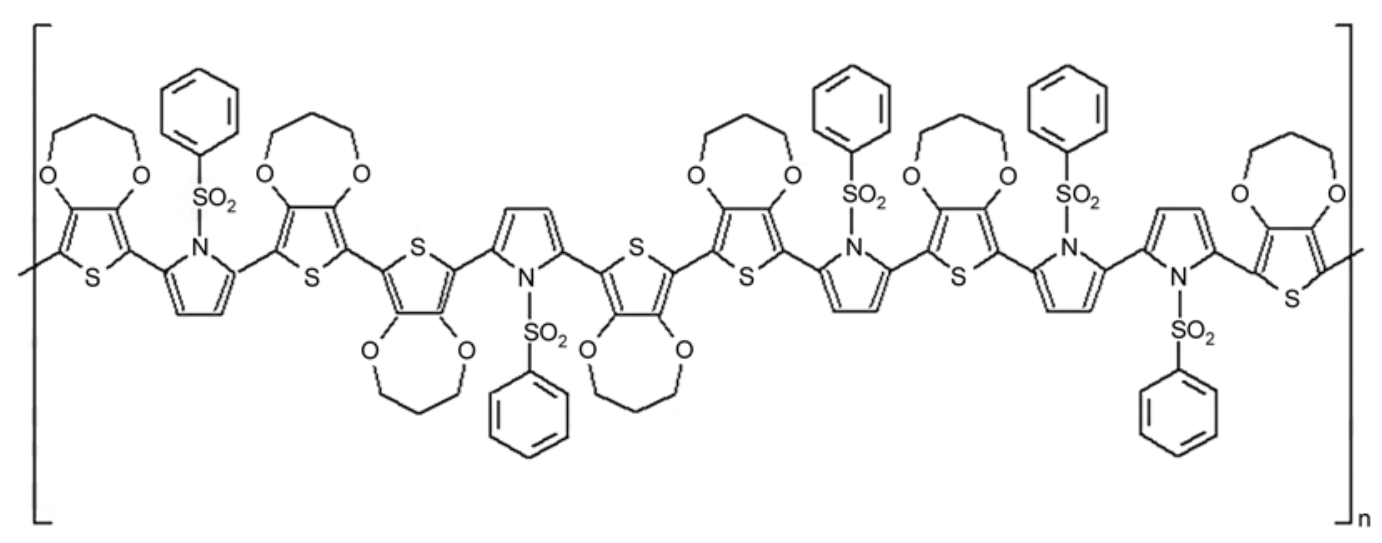

Figure 4. Chemical structure of random Poly(ProDOT-co-PSP) 


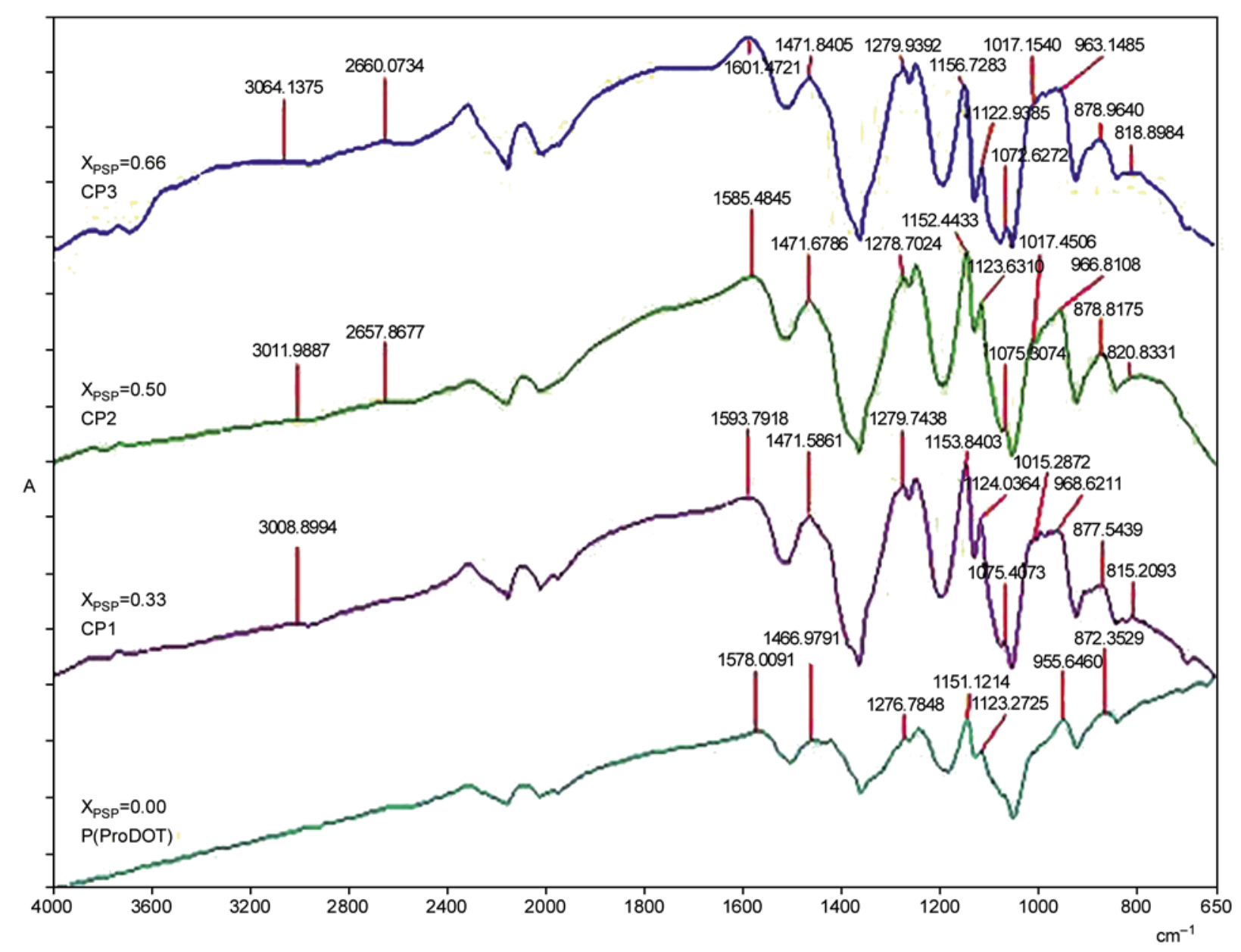

Figure 5. Ex-Situ FTIR-ATR spectrum of Poly(ProDOT-co-PSP) and Poly(ProDOT) films on ITO-PET

Table 2. FTIR-ATR assignments of Poly(ProDOT-co-PSP)s and Poly(ProDOT)

\begin{tabular}{|c|c|c|c|c|}
\hline$\left[\mathrm{cm}^{-1}\right]$ & Poly(ProDOT) & CP1 & CP2 & CP3 \\
\hline $\mathrm{C}-\mathrm{H}$ stretching (aromatic) & - & 3008 & 3011 & 3064 \\
\hline C-H deformation (aromatic) & - & - & 2657 & 2660 \\
\hline $\mathrm{CH}_{2}$ wagging & 1123 & 1122 & 1124 & 1123 \\
\hline $\mathrm{C}=\mathrm{C}$ stretching (thiophene ring) & 1466 & 1471 & 1471 & 1471 \\
\hline Sulfonyl stretching & - & 1075 & 1075 & 1072 \\
\hline The stretching quonidal structure of thiophene & 1276 & 1279 & 1278 & 1279 \\
\hline $\mathrm{C}-\mathrm{O}-\mathrm{C}$ group stretching & 1151 & 1153 & 1152 & 1156 \\
\hline $\mathrm{C}-\mathrm{N}$ stretching (N-substitued pyrrole) & - & 1015 & 1018 & 1017 \\
\hline $\mathrm{C}-\mathrm{O}$ bending & 955 & 963 & 968 & 966 \\
\hline $\mathrm{C}-\mathrm{H}$ bending (aromatic) & - & 815 & 820 & 818 \\
\hline $\mathrm{C}-\mathrm{S}$ stretching & 872 & 877 & 878 & 879 \\
\hline
\end{tabular}

The band at $1466-1471 \mathrm{~cm}^{-1}$ (stretching of $\mathrm{C}=\mathrm{C}$ bond) and the peak at $1276-1279 \mathrm{~cm}^{-1}$ (the stretching quinoidal structure of thiophene) are known to be characteristic vibrational peaks of polythiophene. Vibrations at $1151-1156 \mathrm{~cm}^{-1}$ are assigned to stretching in the alkylenedioxy group $(\mathrm{C}-\mathrm{O}-\mathrm{C}$ bond). The band at $1015-1018 \mathrm{~cm}^{-1}$ (C-N stretching) originated from the $\mathrm{N}$-substitued pyrrole of PSP. Sulfonyl stretching at $1072-1075 \mathrm{~cm}^{-1}$, aromatic $\mathrm{C}-\mathrm{H}$ bending $\left(815-820 \mathrm{~cm}^{-1}\right)$ and aromatic
C-H stretching (3008-3064 $\left.\mathrm{cm}^{-1}\right)$ become distinct when PSP ratio is increased in the copolymer. Further vibrations from the $\mathrm{C}-\mathrm{S}$ bond, in the thiophene ring, can be seen at $872-879 \mathrm{~cm}^{-1}$, attributed to $\mathrm{C}-\mathrm{S}$ stretching. All assignments were denoted in Table 2.

\subsection{Morphological analysis of Poly(ProDOT-co-PSP) films}

The morphologies of copolymer coatings onto SCMFEs were investigated by SEM (Figure 6). By 
using small size electrolyte anions as $\mathrm{ClO}_{4}^{-}$, a high density of pores was obtained in the films. SEM images of copolymers of this study have similar porous structure with ProDOT-Et ${ }_{2}$ [57]. The observed differences at film thicknesses were obtained due to an increase of PSP in the feed (Table 1).

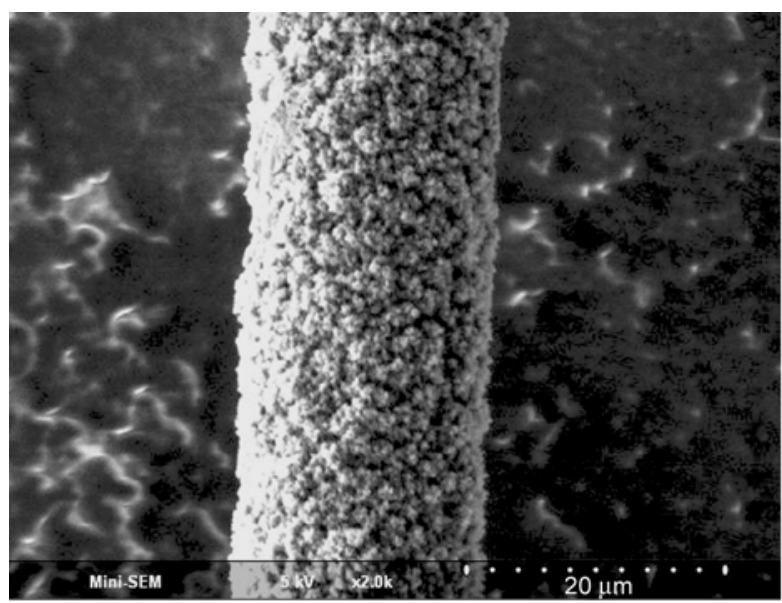

a)
This thickness difference helps us to follow the incorporation of PSP into the copolymer structure. The difference in the capacitance is also due to change of film thickness and fiber morphology in the course of their modification. A continuous increase in current with successive scans is observed,

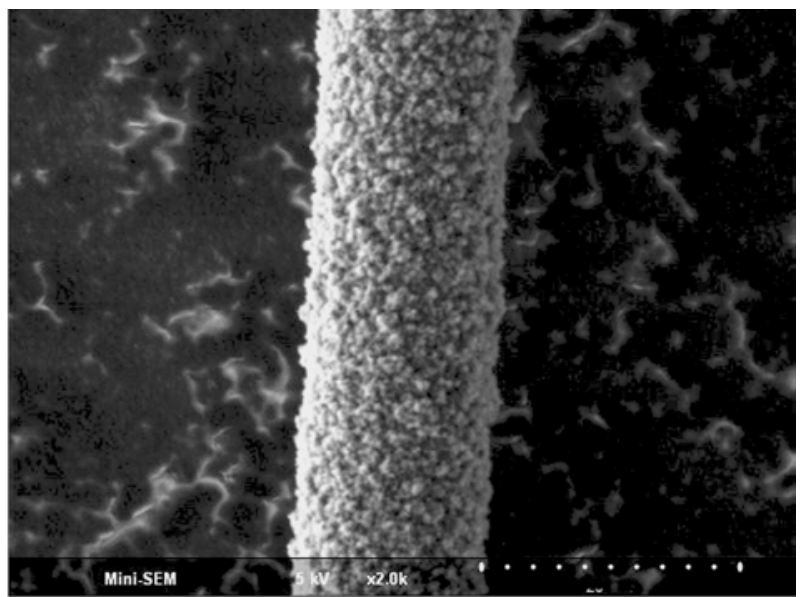

b)

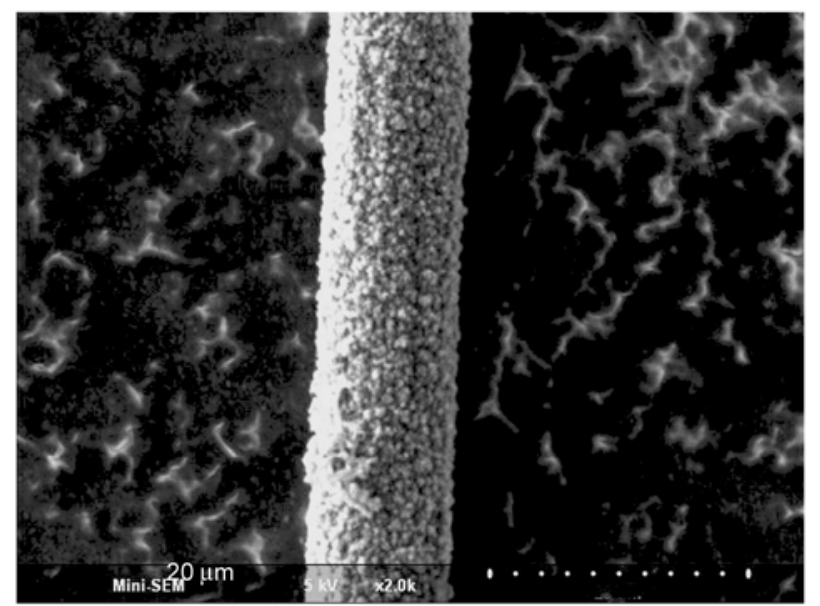

c)

Figure 6. SEM images of CP1 (a), CP2 (b) and CP3 (c) electrocoated onto SCMFE in $0.1 \mathrm{M} \mathrm{NaClO}_{4} / \mathrm{ACN}$ after 10 cycles
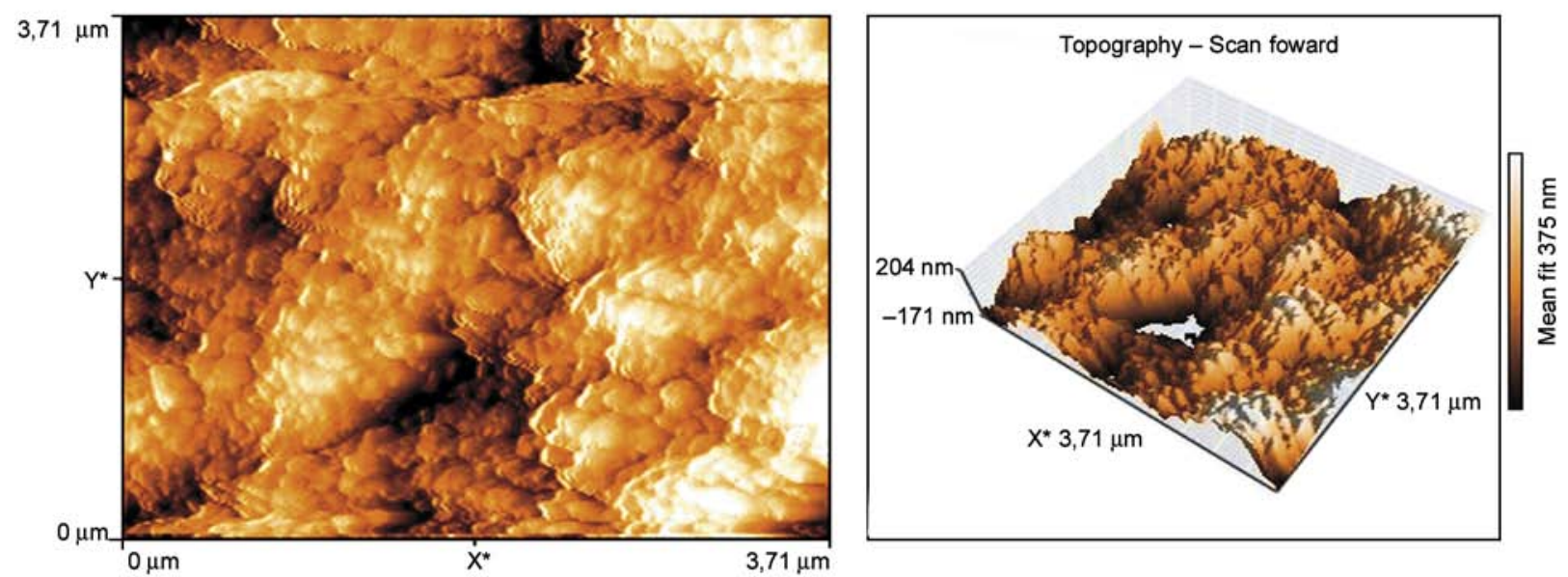

a)

b)

Figure 7. AFM (a) and 3D AFM (b) topographies of the silicon wafer electrode surface after modification with the CP1 


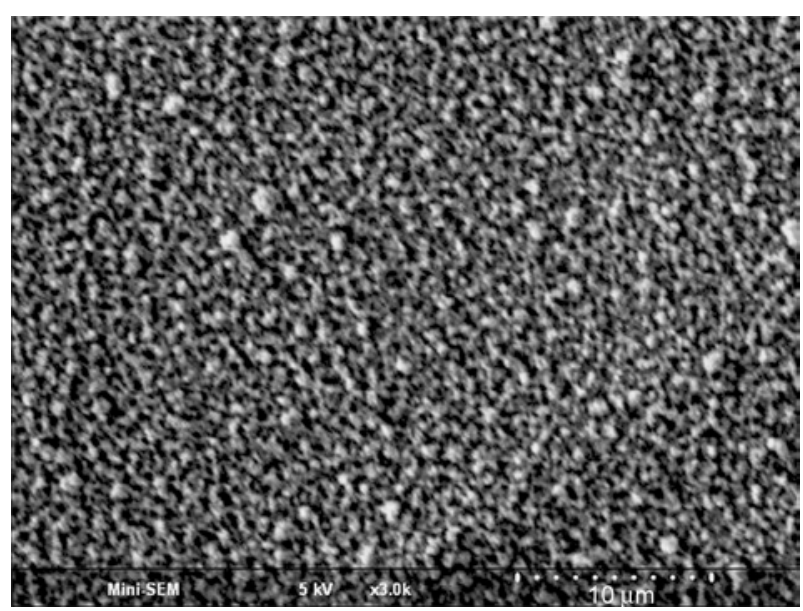

Figure 8. SEM image of the silicon wafer electrode surface after modification with the CP1

indicating an increase in the thickness, and also in the conductivity of the polymeric film formed on the electrode surface, which is followed by CV measurements [58].

The monomer mixture of ProDOT $(10 \mathrm{mM})$ and PSP ( $5 \mathrm{mM})$ was copolymerized at constant potential $(1.0 \mathrm{~V})$ by chronoamperometry onto silicon wafer for AFM analysis. The images were obtained at none-contact mode AFM (Figure 7). Root mean square (RMS), roughness value was calculated via Nanosurf Easyscan 2 software program by selecting raw data (RMS: $65.8 \mathrm{~nm}$ ). The SEM image was also obtained for modified silicon wafer (Figure 8). These spherical-shape aggregates were obtained by the growth of much smaller nanoscale aggregates dependent on the polymerization charge.

\subsection{Electrochemical Impedance Spectroscopy}

The electrical properties of Poly(ProDOT) and copolymers on SCFMEs were determined by electrochemical impedance measurements in monomer free solution. The Nyquist, Bode Magnitude and Bode Phase plots of thin films were given in the frequency range $0.01 \mathrm{~Hz}-100 \mathrm{kHz}$ (Figure 9a-c).

The copolymers are also exhibiting different impedance data from that of Poly(ProDOT) which shown an ideal capacitive line (Bode phase angles close to $90^{\circ}$ ) by the application of electrochemical impedance spectroscopic measurements, indicating fast charge transfer at the carbon fiber/polymer and polymer/solution interfaces, as well as fast charge transport in the polymer bulk. Bode-phase angles which approached the maximum at $0.01 \mathrm{~Hz}$ were $66.99^{\circ}$ for $\mathrm{CP} 1, \sim 51.18^{\circ}$ for $\mathrm{CP} 2$ and $\sim 43.28^{\circ}$ for
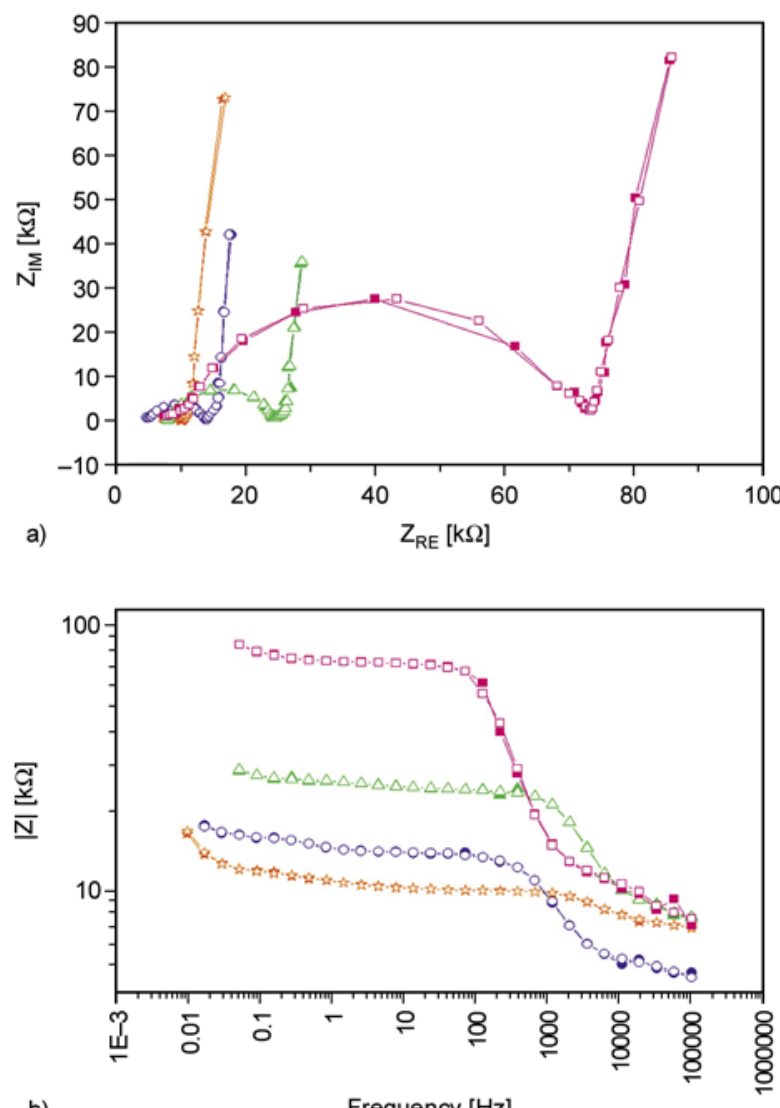

b)

Frequency $[\mathrm{Hz}]$

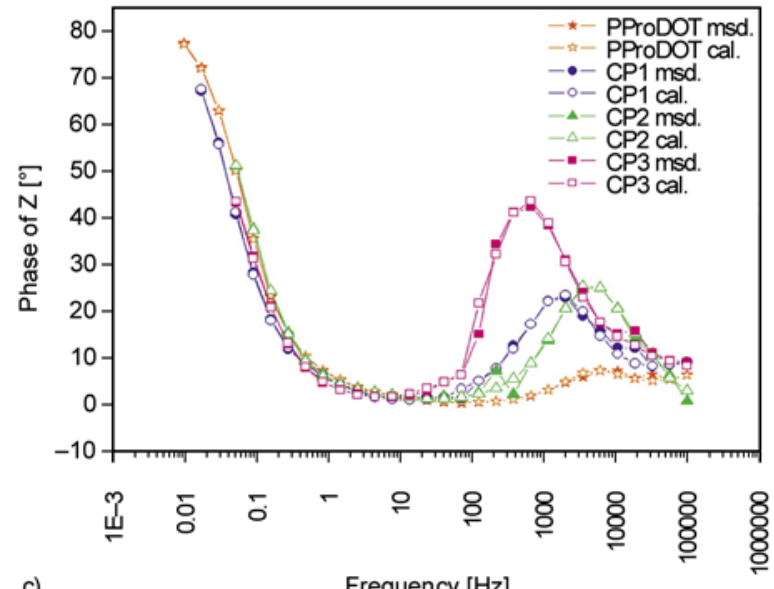

Figure 9. (a) Nyquist (b) Bode magnitude (c) Bode phase plots of of different mole fractions of Poly (ProDOT-co-PSP) electrografted on SCFMEs; correlated with the calculated data from the equivalent circuit modelling; $(\mathrm{R}(\mathrm{W}(\mathrm{CR})(\mathrm{QR}))(\mathrm{CR}))$

CP3, respectively, (Figure 9c). That indicates the presence of PSP in copolymer structure. The Bodephase peaks of the copolymers in the frequency range of $10 \mathrm{~Hz}-10000 \mathrm{~Hz}$ appeared which should be caused by the transition from resistor to capacitor with the increase of PSP ratio. The Bode magnitude plots for copolymers were presented in Fig- 
ure $9 \mathrm{~b}, \mathrm{CP} 1$ had higher conductivity compared to $\mathrm{CP} 2$ and $\mathrm{CP} 3$. Nyquist plots were also used to estimate the low-frequency redox capacitance $\left(C_{\mathrm{LF}}\right)$ of the copolymer-modified SCFMEs. It can be evaluated from the equation $C_{\mathrm{LF}}=-1 /\left(2 \pi \cdot f \cdot Z_{\mathrm{IM}}\right)$, where $Z_{\mathrm{IM}}$ is the obtained from the slope of a plot of the imaginary component of the impedance at low frequencies versus inverse of the reciprocal frequency $f(f=0.01 \mathrm{~Hz})$ and other symbols have their usual meanings.

The $C_{\mathrm{LF}}$ and film thickness of copolymers decreased which indicates the increase of PSP concentration in the feed. Total charges were obtained during electrogrowth process as 7.184, 5.489 and $3.305 \mathrm{mC}$ (Table 1). The increase of PSP concentration in the feed resulted the decrease in film thickness and growth rate of copolymer. This is confirmed by the

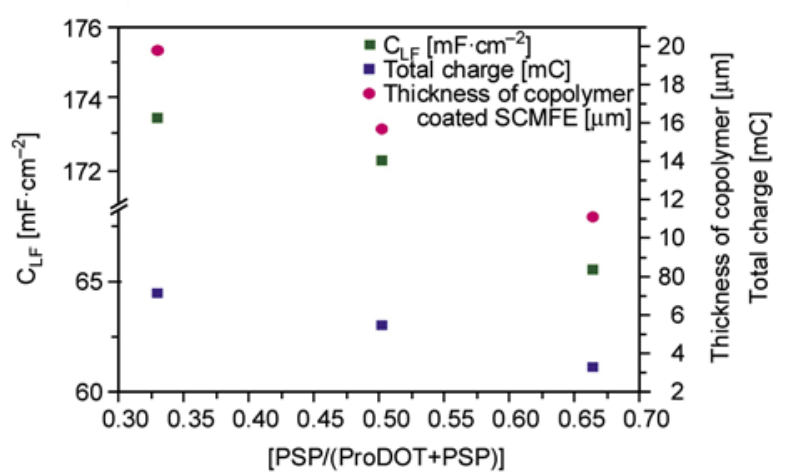

Figure 10. Thicknesses of copolymer coated SCFMEs obtained from SEM, low frequency capacitances and total charges $(\Delta Q)$ which were applied during the electropolymerization, for different mole fractions of Poly(ProDOT-co-PSP)

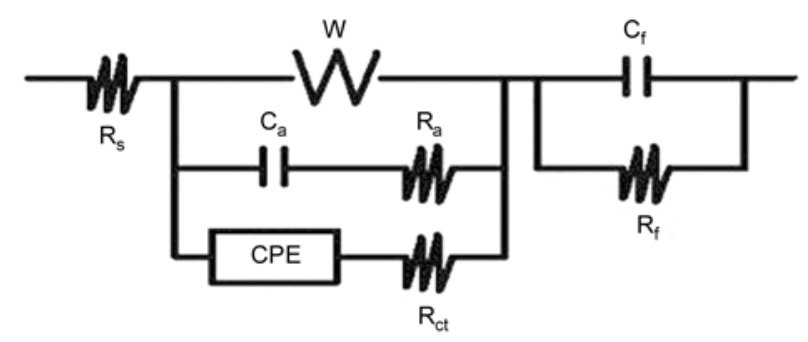

Figure 11. The equivalent circuit model of Poly(ProDOT), $\mathrm{CP} 1, \mathrm{CP} 2$ and $\mathrm{CP} 3$ coating on a single carbon fiber electrode. $\left(R_{\mathrm{S}}=\right.$ solution and pore resistance and $W=$ Warburg impedance, $Z_{\mathrm{W}} ; R_{\mathrm{a}}$ and $C_{\mathrm{a}}$ are the resistance and the adsorption capacitance; $R_{\mathrm{ct}}=$ charge transfer resistance; CPE is used for modelling the double layer capacitance, $C_{\mathrm{dl}} ; R_{\mathrm{f}}$ and $C_{\mathrm{f}}$ are film resistance and film capacitance of coated copolymer film on carbon fiber microelectrode) cyclic voltammetry of mixture of monomers, the decrease found in the total charge, film thickness and $C_{\mathrm{LF}}$ in the plot of it against PSP mole fraction of copolymer (Figure 10).

The Nyquist plots (complex plane plots) were semicircles and formed under ideal conditions for biosensing [59]. The diameter of the semi-circle increased with an increase of PSP in the feed that destroys the integrated aromatic system of thiophene. It corresponds to the charge transfer resistance which included in the equivalent circuit (Figure 11) as the resistance of the modified electrode.

\subsection{Electrical equivalent circuit}

The EIS data were fitted with an equivalent electrical circuit in order to characterize the electrochemical properties of copolymer. The experimental results obtained from equivalent circuit have shown that both the double-layer and the film capacitances decreased with the increase of incorporated PSP ratio into copolymer structure, while the chargetransfer and the pore resistance increased.

The most widely used is the constant phase element (CPE), which has a non-integer power dependence on the frequency. CPE is used in a model in place of a capacitor $C_{\mathrm{dl}}$ (double layer capacity) to compensate for roughness of the electrode, porosity and nonhomogeneity in the system. A rough or porous surface can cause a double-layer capacitance to appear as a CPE with a $n$ value between 0.9 and 1 [60]. In this study, CPE was used as double layer capacitance due to a porous structure $(n \sim 1)$ (Table 3 ). The impedance spectra for copolymers may be described by the equivalent circuit of Figure 11, $(\mathrm{R}(\mathrm{W}(\mathrm{CR})(\mathrm{QR}))(\mathrm{CR}))$. The model is composed of the electrolyte and pore resistance $\left(R_{\mathrm{S}}\right)$, the adsorption capacitance and resistance $\left(C_{\mathrm{a}}\right.$ and $\left.R_{\mathrm{a}}\right)$, doublelayer capacitance and charge-transfer resistance $\left(C_{\mathrm{dl}}\right.$ and $\left.R_{\mathrm{ct}}\right)$, Warburg impedance $(W)$, resitance and capacitance of the copolymer film onto SCMFE $\left(R_{\mathrm{f}}\right.$ and $C_{\mathrm{f}}$ ). $R_{\mathrm{a}}$ and $C_{\mathrm{a}}$ connected with the charging/discharging process in the surface of the film. Both of these parameters improve the quality-of-fit of the frequency dispersion transition between the charge transfer semi-circle and the Warburg impedance or capacitance line. $C_{\mathrm{dl}}$ and $R_{\mathrm{ct}}$ formed by the inward penetration of $\mathrm{ClO}_{4}^{-}$anion along pores at the electrolyte|copolymer interface. $W$ is related to diffusion of species along the micropores and depends 
Table 3. Mole fraction dependence of parameters calculated from the equivalent circuit model for Poly(ProDOT) and Poly(ProDOT-co-PSP) films on SCFME

\begin{tabular}{|l|c|c|c|c|}
\hline & Poly(ProDOT) & CP1 & CP2 & CP3 \\
\hline$R_{\mathrm{S}}\left[\Omega \cdot \mathrm{cm}^{2}\right]$ & 2.528 & 4.738 & 12.574 & 14.656 \\
\hline$W / Y_{0}\left[\mu \mathrm{S} \cdot \mathrm{s}^{-\mathrm{n}} \cdot \mathrm{cm}^{-2}\right]$ & 0.0253 & 0.218 & 0.278 & 0.528 \\
\hline$C_{\mathrm{a}}\left[\mathrm{mF} \cdot \mathrm{cm}^{-2}\right]$ & 92.35 & 41.35 & 27.98 & 5.08 \\
\hline$R_{\mathrm{a}}\left[\Omega \cdot \mathrm{cm}^{2}\right]$ & 8.25 & 11.37 & 15.57 & 34.06 \\
\hline$C_{\mathrm{dl}}\left[\mathrm{mF} \cdot \mathrm{cm}^{-2}\right]$ & 466.95 & 176.05 & 118.80 & 55.30 \\
\hline$n$ & 0.946 & 0.974 & 0.902 & 0.906 \\
\hline$R_{\mathrm{ct}}\left[\Omega \cdot \mathrm{cm}^{2}\right]$ & 19.75 & 41.66 & 78.34 & 167.84 \\
\hline$C_{\mathrm{f}}\left[\mathrm{mF} \cdot \mathrm{cm}^{-2}\right]$ & 117.22 & 0.02 & 0.013 & 0.0053 \\
\hline$R_{\mathrm{f}}\left[\Omega \cdot \mathrm{cm}^{2}\right]$ & 3.85 & 19.19 & 25.26 & 107.60 \\
\hline Chi Squred, $\chi^{2}$ & $1.955 \cdot 10^{-4}$ & $7.565 \cdot 10^{-4}$ & $7.878 \cdot 10^{-4}$ & $2.969 \cdot 10^{-3}$ \\
\hline
\end{tabular}

on the electrode geometry (spherical diffusion at microelectrode).

At Nyquist plots of copolymers, appeared semi-circle in high frequency range was associated with anion transfer at the film|solution interface and can be described by the charge transfer resistance $R_{\mathrm{ct}}$, in series combination with a CPE. The increase in diameter of the circle, i.e., higher the charge transfer resistance $\left(R_{\mathrm{ct}}\right)$, is most useful for biosensing [59]. After the charge transfer semi-circle, straight line at the $x$-axis can be related to Warburg impedance, $Z_{\mathrm{W}}$, due to the diffusion of charged species in the film at low frequency.

The copolymers have high electrolyte and pore resistivity $\left(R_{\mathrm{s}}\right)$, resulting from the decrease in pore size and film thickness, making it more difficult to maintain connectivity between the pores and causing the lowest interfacial area for charge transport. Film capacitance $\left(C_{\mathrm{f}}\right)$, double-layer capacitance $\left(C_{\mathrm{dl}}\right)$ and adsorption capacitance $\left(C_{\mathrm{a}}\right)$ were found to be inversely proportional to the concentration of PSP (Figure 12).

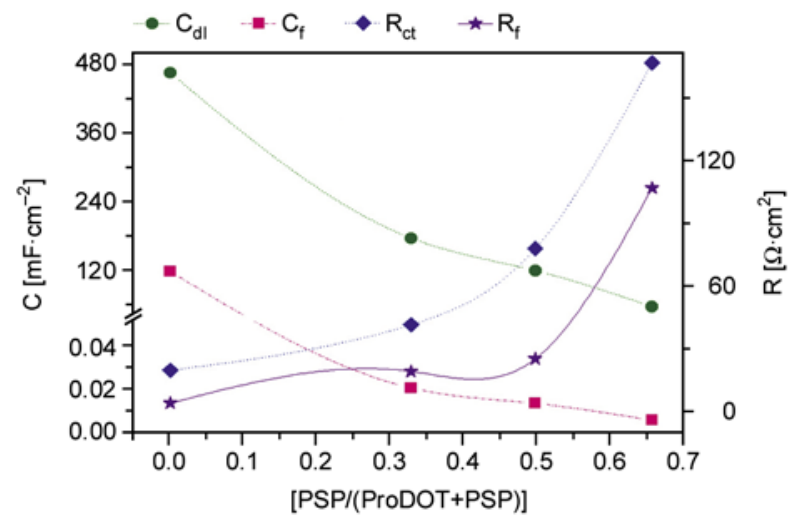

Figure 12. Charge transfer $\left(R_{\mathrm{ct}}\right)$ and film $\left(R_{\mathrm{f}}\right)$ resistances; double layer $\left(C_{\mathrm{dl}}\right)$ and film $\left(C_{\mathrm{f}}\right)$ capacitances obtained by fitting experimental data to the equivalent circuit model for Poly(ProDOT), $\mathrm{CP} 1, \mathrm{CP} 2$ and $\mathrm{CP} 3$

\section{Conclusions}

A new copolymer, obtained from ProDOT and PSP by the cyclic voltammetry, was successfully synthesized. The experimental results from CV and EIS and the theoretical results obtained from equivalent circuit combined with morphological characterization. FTIR-ATR characteristic peaks of PSP indicate the inclusion into copolymer. A decrease in peak currents and total charges of copolymer was observed as compared to homopolymer of Poly(ProDOT). The changing of the capacitance properties, film thickness and fiber morphology was found to be inversely proportional to the increasing PSP concentration in the feed. These information hints that sulfonyl group in PSP has very strong electronwithdrawing effect thus making it difficult to polymerize electrochemically. The capacitance properties of copolymers at lower frequency become smaller as compared to Poly(ProDOT), hence suggesting an increase in the sulfonyl content in the copolymer due to the addition of PSP, which in turn suggests more sulfonyl structure in the copolymer. The changing of the capacitance of the copolymer is reflected by the equivalent circuit model by the dependency of the mole fractions. The decreasing of the film thickness obtained from SEM and the decrease of capacitance values clearly indicates the inclusion of PSP into copolymer. The well-defined electrochemistry of Poly(ProDOT-co-PSP) films onto SCMFEs opens up the possibility for bioelectrochemical sensor electrodes.

\section{Acknowledgements}

This work was supported by TUBITAK 107 T933 project which was acknowledged. 


\section{References}

[1] Padilla J., Seshadri V., Filloramo J., Mino K., Mishra P., Radmard B., Kumar A., Sotzing A., Otero F.: High contrast solid-state electrochromic devices from substituted 3,4-propylenedioxythiophenes using the dual conjugated polymer approach. Synthetic Metals, 157, 261-268 (2007).

DOI: 10.1016/j.synthmet.2007.03.003

[2] Carpi F., DeRossi D.: Colours from electroactive polymers: Electrochromic, electroluminescent and laser devices based on organic materials. Optics and Laser Technology, 38, 292-305 (2006).

DOI: 10.1016/j.optlastec.2005.06.019

[3] Padilla J., Seshadri V., Otero T. F., Sotzing G. A.: Electrochemical study of dual conjugated polymer electrochromic devices. Journal of Electroanalytical Chemistry, 609, 75-84 (2007).

DOI: 10.1016/j.jelechem.2007.06.008

[4] Kimura G., Yamada K.: Electrochromism of poly(3,4ethylenedioxythiophene) films on Au nano-brush electrode. Synthetic Metals, 159, 914-918 (2009).

DOI: $10.1016 /$ j.synthmet.2009.01.055

[5] Yamada K., Seya K., Kimura G.: Electrochromism of poly(pyrrole) film on Au nano-brush electrode. Synthetic Metals, 159, 188-193 (2009).

DOI: $10.1016 /$ j.synthmet.2008.08.009

[6] Welsh D. M., Kumar A., Morvant M. C., Reynolds J. R.: Fast electrochromic polymers based on new poly (3,4-alkylenedioxythiophene) derivatives. Synthetic Metals, 102, 967-968 (1999).

DOI: 10.1016/S0379-6779(98)01014-5

[7] Camurlu P., Şahmetlioğlu E., Şahin E., Akhmedov I. M., Tanyeli C., Toppare L.: Fine tuning of color via copolymerization and its electrochromic device application. Thin Solid Films, 516, 4139-4144 (2008).

DOI: $10.1016 /$ j.tsf.2007.10.098

[8] Xia X. H., Tu J. P., Zhang J., Huang X. H., Wang X. L., Zhang W. K., Huang H.: Multicolor and fast electrochromism of nanoporous $\mathrm{NiO} /$ poly(3,4-ethylenedioxythiophene) composite thin film. Electrochemistry Communications, 11, 702-705 (2009).

DOI: 10.1016/j.elecom.2009.01.017

[9] Sahoo R., Mishra S. P., Kumar A., Sindhu S., Rao K. N., Gopal E. S. R.: Novel high contrast electrochromic polymer materials based on 3,4-propylenedioxythiophene. Optical Materials, 30, 143-145 (2007).

DOI: $10.1016 /$ j.optmat.2006.11.030

[10] Jain V., Sahoo R., Mishra S. P., Sinha J., Montazami R., Yochum H. M., Heflin J. R., Kumar A.: Synthesis and characterization of regioregular water-soluble 3,4propylenedioxythiophene derivative and its application in the fabrication of high-contrast solid-state electrochromic devices. Electrochromic Devices Macromolecules, 42, 135-140 (2009).

DOI: $10.1021 / \mathrm{ma} 801708 \mathrm{~d}$
[11] Wen Z., Itoh T., Uno T., Kubo M., Wen T., Yamamoto O.: Polymer electrolytes based on poly(ethyleye oxide) and cross-linked poly(ethylene oxide-co-propylene oxide). Solid State Ionics, 175, 739-742 (2004). DOI: $10.1016 /$ j.ssi.2003.10.023

[12] Invernale M. A., Bokria J. G., Ombaba M., Lee K-R., Mamangun D. M. D., Sotzing G. A.: Variable-color poly(3,4-propylenedioxythiophene) electrochromics from precursor polymers. Polymer, 51, 378-382 (2010).

DOI: $10.1016 /$ j.polymer.2009.12.015

[13] Hou Y., Cheng Y., Hobson T., Liu J.: Design and synthesis of hierarchical $\mathrm{MnO}_{2}$ nanospheres/carbon nanotubes/conducting polymer ternary composite for high performance electrochemical electrodes. Nano Letters, 10, 2727-2733 (2010). DOI: $10.1021 /$ NL101723g

[14] Campos L. M., Mozer A. J., Günes S., Winder C., Neugebauer H., Sariciftci N. S., Thompson B. C., Reeves B. D., Grenier C. R. G., Reynolds J. R.: Photovoltaic activity of a PolyProDOT derivative in a bulk heterojunction solar cell. Solar Energy Materials and Solar Cells, 90, 3531-3546 (2006).

DOI: $10.1016 /$ j.solmat.2006.06.051

[15] Hsu C-Y., Chen H-W, Lee K-M., Hu C-W., Ho K-C.: A dye-sensitized photo-supercapacitor based on PProDOTEt2 thick films. Journal of Power Sources, 195, 62326238 (2010).

DOI: 10.1016/j.jpowsour.2009.12.099

[16] Sarac A. S., Gilsing H-D., Gencturk A., Schulz B.: Electrochemically polymerized 2,2-dimethyl-3,4-propylenedioxythiophene on carbon fiber for microsupercapacitor. Progress in Organic Coatings, 60, 281-286 (2007).

DOI: $10.1016 /$ j.porgcoat.2007.07.025

[17] Ates M., Sarac A. S.: Conducting polymer coated carbon surfaces and biosensor applications. Progress in Organic Coatings, 66, 337-358 (2009).

DOI: $10.1016 /$ j.porgcoat.2009.08.014

[18] Xia L., Wei Z., Wan M.: Conducting polymer nanostructures and their application in biosensors. Journal of Colloid and Interface Science, 341, 1-11(2010). DOI: $10.1016 /$ j.jcis.2009.09.029

[19] Tourillon G., Garnier F.: Structural effect on the electrochemical properties of polythiophene and derivatives. Journal of Electroanalytical Chemistry and Interfacial Electrochemistry, 161, 51-58 (1984). DOI: 10.1016/S0022-0728(84)80249-1

[20] Kumar A., Welsh D. M., Morvant M. C., Piroux F., Abboud K. A., Reynolds J. R.: Conducting poly(3,4alkylenedioxythiophene) derivatives as fast electrochromics with high-contrast ratios. Chemistryl of Materials, 10, 896-902 (1998).

DOI: $10.1021 / \mathrm{cm} 9706614$ 
[21] Gaupp C. L., Welsh D. M., Rauh R. D., Reynolds J. R.: Poly(ProDOT-Et2): A high-contrast, high-coloration efficiency electrochromic polymer. Macromolecules Rapid Communications, 23, 885-889 (2002).

DOI: 10.1002/1521-3927(20021001)23:15<885::AID-

\section{MARC885>3.0.CO;2-X}

[22] Sinha J., Sahoo R., Kumar A.: Processable, regioregular, and 'click'able monomer and polymers based on 3,4-propylenedioxythiophene with tunable solubility. Macromolecules, 42, 2015-2022 (2009).

DOI: $10.1021 / \mathrm{ma} 802289 \mathrm{j}$

[23] Mishra S. P., Sahoo R., Ambade A. V., Contractor A. Q., Kumar A.: Synthesis and characterization of functionalized 3,4-propylenedioxythiophene and its derivatives. Journal of Materials Chemistry, 14, 1896-1900 (2004).

DOI: 10.1039/B404600E

[24] Kumar N. A., Kim S. H., Cho B. G., Lim K. T., Jeong Y. T.: Surface functionalization of multiwalled carbon nanotubes with poly(3,4-propylenedioxythiophene) and preparation of its random copolymers: New hybrid materials. Colloid and Polymer Science, 287, 97-102 (2009). DOI: $10.1007 / \mathrm{s} 00396-008-1945-4$

[25] Oberlin A.: Carbonization and graphitization. Carbon, 22, 521-541 (1984). DOI: $10.1016 / 0008-6223(84) 90086-1$

[26] Ates M., Sarac A. S.: Electrochemical impedance spectroscopy of poly[carbazole-co-N-p-tolylsulfonyl pyrrole] on carbon fiber microelectrodes, equivalent circuits for modelling. Progress in Organic Coatings, 65, 281-287 (2009).

DOI: 10.1016/j.porgcoat.2008.12.007

[27] Sarac A. S., Sezgin S., Ates M., Turhan C. M.: Electrochemical impedance spectroscopy and morphological analyses of pyrrole, phenylpyrrole and methoxyphenylpyrrole on carbon fiber microelectrodes. Surface Coatings Technology, 202, 3997-4005 (2008). DOI: $10.1016 /$ j.surfcoat.2008.02.007

[28] Sarac A. S., Sezgin S., Ates M., Turhan C. M., Parlak E. A., Irfanoglu B.: Electrochemical impedance spectroscopy of poly(N-methyl pyrrole) on carbon fiber microelectrodes and morphology. Progress in Organic Coatings, 62, 331-335 (2008).

DOI: 10.1016/j.porgcoat.2008.01.016

[29] Tezcan C., Sarac A. S.: Electrochemical copolymerization of 3,4-Ethylenedioxythiophene and $N$-Phenylsulfonyl Pyrrole: Morphologic, spectroscopic, electrochemical characterizations. Journal of the Electrochemical Society, 157, 99-105 (2010).

DOI: $10.1149 / 1.3490420$

[30] Sarac A. S., Ates M., Parlak E. A.: Comparative study of chemical and electrochemical copolymerization of $\mathrm{N}$-methylpyrrole with N-ethylcarbazole spectroscopic and cyclic voltammetric analysis. International Journal of Polymeric Materials, 54, 883-897 (2005).

DOI: $10.1080 / 009140390504861$
[31] Sarac A. S., Ates M., Parlak E. A.: Electrolyte and solvent effects of electrocoated polycarbazole thin films on carbon fiber microelectrodes. Journal of Applied Electrochemistry, 36, 889-898 (2006).

DOI: $10.1007 / \mathrm{s} 10800-006-9145-8$

[32] Sarac A. S., Serantoni M., Tofail S. A. M., Henry J., Cunnane V. J., McMonagle J. B.: Characterisation of nanosize thin films of electrografted $\mathrm{N}$-vinylcarbazole copolymers ( $\mathrm{P}[\mathrm{NVCz}-\mathrm{co}-\mathrm{VBSA}]$ and $\mathrm{P}[\mathrm{NVCz}-\mathrm{co}-3-$ MeTh]) onto carbon fibre: AFM, XPS, and Raman spectroscopy. Applied Surface Science, 243, 183-198 (2005).

DOI: $10.1016 /$ j.apsusc.2004.09.095

[33] Sarac A. S., Serantoni M., Tofail S. A. M., Cunnane V. J.: Morphological and spectroscopic analyses of poly[N-vinylcarbazole-co-vinylbenzenesulfonic acid] copolymer electrografted on carbon fiber: The effect of current density. Applied Surface Science, 229, 1318 (2004).

DOI: $10.1016 /$ j.apsusc.2004.02.005

[34] Popkirov G. S., Barsoukov E., Schindler R. N.: Investigation of conducting polymer electrodes by impedance spectroscopy during electropolymerization under galvanostatic conditions. Journal of Electroanalytical Chemistry, 425, 209-216 (1997).

DOI: $10.1016 / \mathrm{S} 0022-0728(96) 04965-0$

[35] Deslouis C., Musiani M. M., Tribollet B., Vorotyntsev M. A.: Comparison of the AC impedance of conducting polymer films studied as electrode-supported and freestanding membranes. Journal of Electrochemical Society, 142, 1902-1908 (1995).

DOI: $10.1149 / 1.2044212$

[36] Láng G., Inzelt G.: Some problems connected with impedance analysis of polymer film electrodes: Effect of the film thickness and the thickness distribution. Electrochimica Acta, 36, 847-854 (1991). DOI: 10.1016/0013-4686(91)85284-E

[37] Parsons R.: The electrical double layer: Recent experimental and theoretical developments. Chemical Reviews, 90, 813-826 (1990).

DOI: $10.1021 / \mathrm{cr} 00103 \mathrm{a} 008$

[38] Vorotyntsev M. A., Badiali J-P., Inzelt G.: Electrochemical impedance spectroscopy of thin films with two mobile charge carriers: Effects of the interfacial charging. Journal of Electroanalytical Chemistry, 472, 7-19 (1999). DOI: 10.1016/S0022-0728(99)00253-3

[39] Abidian M. R., Martin D. C.: Experimental and theoretical characterization of implantable neural microelectrodes modified with conducting polymer nanotubes. Biomaterials, 29, 1273-1283 (2008). DOI: 10.1016/j.biomaterials.2007.11.022

[40] Bobacka J., Grzeszczuk M., Ivaska A.: Electron transfer at conducting polymer film electrodes: Mechanism and kinetics of ferrocene oxidation at poly(3-octylthiophene). Journal of Electroanalytical Chemistry, 427, 63-69 (1997). DOI: $10.1016 / \mathrm{S} 0022-0728(96) 05023-1$ 
[41] Bobacka J., Lewenstam A., Ivaska A.: Electrochemical impedance spectroscopy of oxidized poly(3,4-ethylenedioxythiophene) film electrodes in aqueous solutions. Journal of Electroanalytical Chemistry, 489, 1727 (2000).

DOI: 10.1016/S0022-0728(00)00206-0

[42] Mansfeld F. Kendig M. W.: Evaluation of anodized aluminum surfaces with electrochemical impedance spectroscopy. Journal of Electrochemical Society, 135, 828-833 (1988).

DOI: $10.1149 / 1.2095786$

[43] Khaled K. F.: The inhibition of benzimidazole derivatives on corrosion of iron in $1 \mathrm{M} \mathrm{HCl}$ solutions. Electrochimica Acta, 48, 2493-2503 (2003).

DOI: 10.1016/S0013-4686(03)00291-3

[44] Carnot A., Frateur I., Zanna S., Tribollet B., DuboisBrugger I., Marcus P.: Corrosion mechanisms of steel concrete moulds in contact with a demoulding agent studied by EIS and XPS. Corrosion Science, 45, 25132524 (2003).

DOI: $10.1016 / \mathrm{S} 0010-938 X(03) 00076-3$

[45] Aziz I., Zhang Q., Xiang M.: Using EIS to evaluate anti-corrosion properties of the $\mathrm{SiCp} / 5 \mathrm{~A} 06$ aluminium MMC treated by cerium conversion coatings. Journal of Rare Earths, 28, 109-116 (2010).

DOI: 10.1016/S1002-0721(09)60062-4

[46] Simões A. M., Fernandes J. C. S.: Studying phosphate corrosion inhibition at the cut edge of coil coated galvanized steel using the SVET and EIS. Progress in Organic Coatings, 69, 219-224 (2010).

DOI: $10.1016 /$ j.porgcoat.2010.04.022

[47] Farelas F., Galicia M., Brown B., Nesic S., Castaneda H.: Evolution of dissolution processes at the interface of carbon steel corroding in a $\mathrm{CO}_{2}$ environment studied by EIS. Corrosion Science, 52, 509-517 (2010). DOI: 10.1016/j.corsci.2009.10.007

[48] de Lacy Castello B. P. J., Evans P., Guernion N., Ratcliffe N. M., Sivanand P. S., Teare G. G.: The synthesis of a number of 3-alkyl and 3-carboxy subtituted pyrroles: Their chemical polymerisation onto poly (vinylidene fluoride) membranes and their use as gas senstive resistor. Synthetic Metals, 114, 181-188 (2000). DOI: 10.1016/S0379-6779(00)00250-2

[49] Janosik T., Shirani H., Whalstörm N., Malky I., Stensland J., Bergman J.: Efficient sulfonation of 1-phenylsulfonyl-1H-pyrroles and 1-phenylsulfonyl-1 $H$-indoles using chlorosulfonic acid in acetonitrile. Tetrahedron, 62, 1699-1707 (2006).

DOI: $10.1002 /$ chin.200624113

[50] Li X-G., Huang M-R., Duan W., Yang Y-L.: Novel multifunctional polymers from aromatic diamines by oxidative polymerizations. Chemical Reviews, 102, 2925-3030 (2002).

DOI: $10.1002 /$ chin.200246251
[51] Lu Q. F., Huang M. R., Li X. G.: Synthesis and heavymetal-ion sorption of pure sulfophenylenediamine copolymer nanoparticles with intrinsic conductivity and stability. Chemistry A: European Journal, 13, 6009-6018 (2007).

DOI: $10.1002 /$ chem.200700233

[52] Malinauskas A.: Chemical deposition of conducting polymers. Polymer, 42, 3957-3972 (2001).

DOI: 10.1016/S0032-3861(00)00800-4

[53] Prévost V., Petit A., Pla F.: Studies on chemical oxidative copolymerization of aniline and o-alkoxysulfonated anilines: I. Synthesis and characterization of novel self-doped polyanilines. Synthetic Metals, 104, 79-87 (1999)

DOI: 10.1016/S0379-6779(99)00009-0

[54] Fu G. D., Zhao J. P., Sun Y. M., Kang E. T., Neoh K. G.: Conductive hollow nanospheres of polyaniline via surface-1nitiated atom transfer radical polymerization of 4-vinylaniline and oxidative graft copolymerization of aniline. Macromolecules, 40, 2271-2275 (2007). DOI: $10.1021 / \mathrm{ma} 0613988$

[55] Li X-G., Duan W., Huang M-R., Rodriguez L. N. J.: Electrocopolymerization of meta-phenylenediamine and ortho-phenetidine. Reactive and Functional Polymers, 62, 261-270 (2005).

DOI: $10.1016 /$ j.reactfunctpolym.2005.01.001

[56] Ocampo C., Alemán C., Oliver R., Arnedillo M. L., Ruiz O., Estrany F.: Copolymers of N-methylpyrrole and 3,4-ethylenedioxythiophene: Structural, physical and electronic properties. Polymer International, 56, 803-809 (2007).

DOI: $10.1002 /$ pi.2213

[57] Lee K-M., Chen P-Y., Hsu C-Y., Huang J-H., Ho WH., Chen H-C., Ho K-C.: A high-performance counter electrode based on poly(3,4-alkylenedioxythiophene) for dye-sensitized solar cells. Journal of Power Sources, 188, 313-318 (2009).

DOI: 10.1016/j.jpowsour.2008.11.075

[58] Saraç A. S., Bardavit Y.: Electrografting of copolymer of poly[N-vinylcarbazole-co-styrene] and poly[Nvinylcarbazole-co-acrylonitrile] onto carbon fiber: Cyclovoltammetric (CV), spectroscopic (Uv-Vis, FTIR-ATR), and morphological study (SEM). Progress in Organic Coatings, 49, 85-94 (2004).

DOI: 10.1016/j.porgcoat.2003.08.018

[59] Johnsson B., Löfås S., Lindquist G.: Immobilization of proteins to a carboxymethyldextran-modified gold surface for biospecific interaction analysis in surface plasmon resonance sensors. Analytical Biochemistry, 198, 268-277 (1991).

DOI: 10.1016/0003-2697(91)90424-R

[60] Girija T. C., Sangaranarayanan M. V.: Investigation of polyaniline-coated stainless steel electrodes for electrochemical supercapacitors. Synthetic Metals, 156, 244-250 (2006).

DOI: 10.1016/j.synthmet.2005.12.006 